\title{
Decentralized Supply Risk Management
}

\author{
Göker Aydın* $\quad$ Volodymyr Babich ${ }^{\dagger} \quad$ Damian R. Beil ${ }^{\ddagger} \quad$ Zhibin (Ben) Yang ${ }^{\S}$
}

July 28, 2009

\section{Introduction}

A paramount concern of today's supply chain managers is building supply chains that can handle supply disruptions. There are a number of reasons why supply chain managers are becoming increasingly preoccupied with supply risk. First, supply disruptions are more likely than before, because the widespread use of outsourcing is not only stretching supply chains further geographically, but it is also turning supply networks into intricate webs of highly interdependent players. In fact, in a 2008 survey of 138 companies, $58 \%$ reported that they suffered financial losses within the last year due to a supply disruption. ${ }^{1}$ Second, outsourcing to external vendors is making supply risks harder to foresee and, therefore, harder to prepare for. Third, the consequences of supply risks have arguably become more costly than before. Successful initiatives such as lean manufacturing, quick response, and postponement proved beneficial in maintaining high fill rates while squeezing inventory out of the pipeline, but they also reduced the buffers that a firm could fall back on in the event of a supply disruption, exacerbating the costly effects of disruptions.

This chapter focuses on supply risk management in decentralized networks where self-interested firms are interacting. In the Introduction we first illustrate several types of risk. We then discuss the operational tools used to manage those risks. We emphasize the challenges and opportunities in supply risk management arising from the decentralized nature of the supply chain and highlight how supply risks influence the interactions among firms in supply networks, review insights into decentralized supply risk management from the extant academic research and point out important future research directions.

\footnotetext{
${ }^{*}$ Department of Industrial \& Operations Engineering, University of Michigan, 1205 Beal Avenue, Ann Arbor, MI 48109. E-mail: ayding@umich.edu

${ }^{\dagger}$ Department of Industrial \& Operations Engineering, University of Michigan, 1205 Beal Avenue, Ann Arbor, MI 48109. E-mail: babich@umich.edu

${ }^{\ddagger}$ Ross School of Business, University of Michigan, 701 Tappan St., Ann Arbor, MI 48109 . E-mail: dbeil@bus.umich.edu

${ }^{\S}$ Department of Industrial \& Operations Engineering, University of Michigan, 1205 Beal Avenue, Ann Arbor, MI 48109. E-mail: zhibiny@umich.edu

${ }^{1}$ For more details, see http://www.infoworld.com/article/08/09/17/Most_companies_lag_in_supply_ chain_risk_management_1.html.
} 


\section{Types of Supply Risk}

The causes of supply disruptions are myriad, including an accident at a supplier facility, natural disasters, bankruptcy of a key supplier, defective parts or components, labor strikes, etc. Despite the diversity of causes, supply risks by and large fall into three categories depending on how they manifest themselves: shortage of a critical part or a loss of supplier capacity; loss of finished goods inventory due to the use of a defective part; and inflated supply cost.

Shortage of a critical part or a loss of supplier capacity: Supply risk events often take the form of parts shortages or loss of supplier capacity. Such events arise in various settings and for a variety of reasons, as the following examples illustrate.

A well-documented instance of parts shortages is the experience of Boeing in the late 1990s. During that period, Boeing had trouble keeping up with demand for commercial aircraft and missed several delivery deadlines. The poor delivery performance was blamed mainly on shortages of parts such as tie rods and bearings (Biddle, 1997b).

In some cases a loss of supplier capacity may occur due to a shift of the supplier's business strategy. A case in point is the medical device manufacturer Beckman Coulter's loss of its supplier Dovatron, who produced customized chips for Beckman Coulter. ${ }^{2}$ After Dovatron was acquired by Flextronics in 2000, Flextronics restructured itself to focus on higher-volume products, and decided it would no longer serve Beckman Coulter, who was purchasing a low-volume specialty product.

There are abundant examples of supplier bankruptcies that threatened to cut the supply of critical parts. For example, bankrupt automotive supplier Collins \& Aikman halted the shipment of parts to Ford's Fusion plant (McCracken, 2006). In some cases, creditors of bankrupt suppliers may try to "hold up" manufacturers, taking advantage of the critical role many suppliers play for manufacturers. A well-known example of a "hold-up" is UPF Thompson vs. Land Rover (Jennings, 2002). In 2001 UPF Thompson, who was the sole supplier of chassis for the Land Rover's Discover model, declared bankruptcy and was taken over by KPMG. KPMG then threatened to halt chassis shipments unless Land Rover made an additional £35 million payment to KPMG.

Likewise, there are many examples of accidents and natural disasters resulting in temporary loss of supplier facilities: examples include the 1999 earthquake in Taiwan that disrupted semiconductor plants making $70 \%$ of the world's graphic chips and $10 \%$ of the world's memory chips (Savage, 1999; Papadakis, 2003); the 1997 fire at Aisin Seiki, the sole supplier of a key component used in the brake system of many Toyota models (Nishiguchi and Beaudet, 1998); and the 2000 fire at a Phillips chip plant which supplied both Nokia and Ericsson (Sheffi, 2005).

Loss of finished goods inventory due to the use of a defective part: Another form of supply risk is the use of a defective input, which results in finished goods that do not meet the buyer's standards. Such supply risks can have very serious consequences and, if not caught early, can result in the

\footnotetext{
${ }^{2}$ For more details, see http://www.callahan-law.com/verdicts-settlements/fraud-beckmancoulter/index.html.
} 
recall of deployed finished goods inventory. For example, following the deaths of numerous pets in 2007, pet food producer Menu Foods Corp. had to recall more than 60 million cans and pouches of dog and cat foods for more than 100 pet-food brands (Myers, 2007). The deaths were later linked to melamine, a poisonous industrial chemical. The melamine was traced to wheat gluten, which Menu Foods (a Canadian firm) had bought from ChemNutra (a U.S.-based supplier), who, unbeknownst to Menu Foods, had decided to outsource it to Xuzhou Anying Biologic Technology Development Co. Ltd. (a Chinese supplier). In the past few years there have been many other similar recalls: examples include the spinach recall in the US spurred by the discovery of batches contaminated with e.coli (Wall Street Journal, 2007), Mattel's recall of toys covered by lead paint (Casey, 2007), and several computer manufacturers recalling their laptops due to defective batteries produced by Sony (Morse, 2006).

Inflated supply costs: Another type of supply risk is related to uncertainty about the cost of inputs. For example, a part that is procured from a distant supplier may quickly become more expensive if rising oil prices lead to a hike in shipping costs. Supply cost risks can also arise in conjunction with shortages. For instance, in 2000, the price of palladium increased sharply when Russia, the main source of this precious metal, held up its supply. Consequently, automotive manufacturers, who use palladium in catalytic converters, suffered a $\$ 100$ increase in per-vehicle production costs (White, 2000).

\section{Managing Supply Risk}

Firms use various tools to manage supply disruption risks. These tools may be proactive (e.g., supplier qualification screening/risk discovery, diversification, or investing in suppliers to reduce the odds of a supply disruption) or reactive (e.g., using external or internal backup sources of supply in the face of a disruption, or applying nonperformance penalties). We next discuss each of these operational risk management tools.

Supplier qualification screening/risk discovery: A buyer can perform qualification screening when selecting a new supplier or can audit its existing suppliers. Such measures allow the buyer to learn more about the supplier, thus allowing the buyer to identify and avoid or rectify weaknesses that may potentially cause disruptions. For example, had Menu Foods or Mattel (see examples above) done thorough and frequent supplier audits, they might have caught the problems that later resulted in recalls.

Investing in suppliers to reduce the odds of a disruption: Buyer investments in suppliers can take many forms, ranging from helping a supplier improve its production processes to providing funds to a financially-unstable supplier to avoid imminent bankruptcy. The latter is what Ford chose to do when faced with the danger that its supplier, Visteon, would go bankrupt: Ford agreed to pay up to $\$ 1.8 \mathrm{~B}$ to avert a bankruptcy (White, 2005).

Multi-sourcing: In many cases a buyer will have the option to source the same part from not 
one, but multiple suppliers. When such an option is exercised, i.e., when the buyer diversifies, the buyer is less vulnerable to risks associated with any one supplier. As such, diversification can help make the buyer more resilient to supply risks such as shortages, defective parts or loss of supplier capacity. On the other hand, when the buyer chooses not to diversify, multi-sourcing results in increased supplier competition, thus yielding benefits to the buyer.

Using external or internal backup sources of supply: In the face of a disruption, the buyer can scramble to create an alternate source of supply. For example, when the fire at Aisin Seiki threatened to halt the production of many Toyota models, Toyota and Aisin Seiki worked together with many other suppliers to create an alternate source. Likewise, when Beckman Coulter lost its supply of chips from Dovatron, it chose to replace the lost supply by building its own in-house production line.

Non-performance penalties: Most supply contracts include provisions for penalties or nonpayment that will be imposed on a supplier in the event that the supplier fails to deliver on its promises. As a last resort, a buyer can choose to sue the supplier to enforce such penalty clauses.

\section{The Role of Decentralization}

Most supply chains are networks of several self-interested firms. The decentralized nature of supply chains is an important consideration in managing supply risk, and it manifests itself in four important ways: misalignment of incentives between buyers and suppliers; competition among suppliers; competition among buyers; and asymmetric information.

Misalignment of incentives between suppliers and buyers: In many buyer - supplier relationships, the supplier's priorities and interests are not necessarily well aligned with those of the buyer. Such misalignments may cause or exacerbate supply risks. For example, the parts shortage that resulted in Boeing's troubles was partly due to suppliers not keeping up with Boeing's major overhaul of its production process to improve its cycle times (Biddle, 1997a). Likewise, in the case of Beckman Coulter, the part which was highly critical to Beckman Coulter was simply an unprofitable specialty product for Dovatron, which is why Flextronics dropped the part after acquiring Dovatron.

Competition among suppliers: Competition among suppliers may decrease as a result of efforts to prevent disruptions. For example, with a multi-sourcing option, when the buyer commits to ordering from only one supplier the suppliers compete harder to win the buyer's business, but when the buyer commits to diversification, i.e. ordering from multiple suppliers, the suppliers have less incentive to compete aggressively. As a general strategy to encourage competition, the buyer may wish to order from suppliers that are very similar, in particular, suppliers that are exposed to the same risks. However, this reduces diversification benefits. Furthermore, supplier competition can be an aggravating factor in causing disruptions. For example, cost competition among suppliers may result in suppliers cutting corners, thereby increasing the chances of defective parts. Similarly, fierce price competition among suppliers may get to the point where the suppliers' profitability is 
threatened so much as to cause financial instability in the supply base.

Competition among buyers: Competition among buyers in a decentralized system can present a number of challenges and opportunities. When multiple buyers rely on the same supplier, competition among buyers may exacerbate the ramifications of a supply disruption. A case in point is the 1999 earthquake in Taiwan, which resulted in a major shortage of chips. This shortage increased the competition for chips among PC manufacturers, causing a five-fold increase in the spot price of chips, thus inflating the input costs of major PC producers by as much as 25\% (Papadakis, 2003). On the other hand, a supplier working with multiple buyers could be more financially viable because it receives multiple subsidies from these buyers. While all buyers may have a stake in keeping the supplier solvent, some might be reluctant to do so, because by helping the joint supplier they are also helping their competitors. Buyers' willingness to support the supplier depends on the volume of business they have with the supplier (e.g., the Big Three in the automotive industry may all utilize the same supplier, but to different extents).

Asymmetric information: In a decentralized supply chain, information about a supplier's vulnerability to a disruption is not readily available to a buyer, and not having access to this information may be very detrimental to a buyer. For example, Land Rover was not aware of the looming bankruptcy of its supplier UPF-Thompson. Hence, once the bankruptcy happened, Land Rover was unprepared and had few options (Jennings, 2002). Menu Foods was not aware that its first-tier supplier, Chem-Nutra, outsourced to a second-tier supplier and it was this second-tier supplier's product that resulted in the pet food contamination (Myers, 2007). Unfortunately, suppliers often will not (or cannot) voluntarily (or credibly) share their reliability information, and buyers have to work to elicit it.

This chapter is organized as follows. Section 2 overviews the literature related to decentralized supply risk management. Subsequent sections address the key issues that arise in managing supply risk in decentralized supply chains. Section 3 discusses misalignment of incentives, Section 4 addresses supplier competition, Section 5 addresses buyer competition, and Section 6 addresses asymmetric information. A discussion of possible future work in decentralized supply risk management are provided in Section 7.

\section{Literature Taxonomies}

There are a number of excellent reviews of the general supply-risk management literature. The most recent of these reviews is Tomlin (2009??), which appears in Chapter ?? of this book. In this chapter we focus on the subset of the supply-risk management literature that deals with decentralized systems. The insights obtained from this work will be discussed in more detail in subsequent sections of this chapter. In this section we provide a taxonomy of the decentralized supply risk management literature. This taxonomy is captured in Table 1, which encapsulates the 
coming discussion in this section.

\section{Decentralization Type}

One classification dimension for the literature taxonomy is the type of decentralization modeled. As discussed in the Introduction, decentralization manifests itself in supply networks in a number of ways: misalignment of incentives between buyers and suppliers, competition among suppliers, competition among buyers, and asymmetric information. The first of these - incentive misalignment — is present in virtually every paper about decentralized supply risk management (see Section 3). However, the other three aspects of decentralization appear separately.

Competition among suppliers: A subset of the literature on supply-risk management explicitly models the presence of two or more suppliers and the competitive interactions among them. This stream of research includes Babich et al. (2007), Babich (2006), Chaturvedi and Martínez-deAlbéniz (2008), Federgruen and Yang (2009), Wan and Beil (2008a,b), and Yang et al. (2009b). For discussion of supplier competition models, please see Section 4.

Competition among buyers: An emerging stream of research recognizes that multiple buyers may compete for uncertain supply, e.g., Deo and Corbett (2008), Tang and Kouvelis (2009), and Wadecki and Babich (2009). See Section 5 for detailed discussion of models incorporating buyer competition.

Asymmetric information: Different types of asymmetric information relevant to supply risk have been studied. Yang et al. (2009a), Chaturvedi and Martínez-de-Albéniz (2008), and Yang et al. (2009b) study asymmetric information about the supplier's likelihood of experiencing a disruption and about the supplier's production cost. Baiman et al. (2000) and Lim (1997) study asymmetric information about the supplier's ability to produce non-defective items. Wan and Beil (2008b) consider asymmetric information about suppliers' production cost. A detailed description of asymmetric information and supply risk models is provided in Section 6 .

\section{Type of Risk Management Tool}

Another literature classification dimension is the type of risk-management tool studied. The Introduction lists a number of tools that can be used to manage supply risks: supplier qualification screening/risk discovery, multi-sourcing, investing in suppliers to reduce the odds of a supply disruption, creating external or internal backup sources of supply in the face of a disruption, and using nonperformance penalties. The following is a classification of papers that study these tools.

Supplier qualification screening/risk discovery: Wan and Beil (2008b) model a setting where suppliers' qualifications are learned through a qualification screening process while Yang et al. (2009a,b) study models in which the buyer designs a menu of contracts to elicit the supplier's true reliability information. See Section 6 for a review of these papers. 
Investing in suppliers to reduce the odds of a disruption: Babich (2009), and Wadecki and Babich (2009) study models where the buyer provides financial subsidies to a supplier, who can then use subsidies to pay for its production costs. Swinney and Netessine (2009) allow a buyer to reduce the odds of a supplier bankruptcy by offering a long-term contract.

Multi-sourcing: Examples of papers that study multi-sourcing are Babich et al. (2007), Babich (2006), Chaturvedi and Martínez-de-Albéniz (2008), Federgruen and Yang (2009), Tang and Kouvelis (2009), Wan and Beil (2008a), and Yang et al. (2009b). These papers are reviewed in Section 4.

Creating external or internal backup sources of supply: Babich (2006) and Yang et al. (2009a) allow the possibility that either the buyer or the supplier or both have access to a source of backup production in the event of a disruption.

Non-performance penalties: Zimmer (2002), Chaturvedi and Martínez-de-Albéniz (2008), and Yang et al. (2009a,b) investigate the use of penalties imposed on a supplier in the event of nondelivery.

\section{Type of Supply Uncertainty}

Another classification dimension for the literature is the type of supply uncertainty. We listed several types of supply risks in the Introduction: shortage of a critical part, loss of finished goods inventory due to a defect, loss of supplier capacity, and inflated supply cost. Some models in the literature (e.g., Deo and Corbett, 2008; Federgruen and Yang, 2009; Tang and Kouvelis, 2009) use proportional random yield models, whereby if the buyer orders $\bar{q}$ units, it receives only a fraction $q=y \bar{q}$ of the quantity ordered, where $y$ is a random number. Other papers (e.g., Zimmer, 2002; Babich, 2009) model supply risk as random capacity, in which case the supplier's random capacity may impede its ability to meet the buyer's order in full. That is, if the buyer orders $\bar{q}$ units, it receives $q=\min (\bar{q}, k y)$, where $k$ is the supplier's regular capacity and $y$ is a random shock. Usually random capacity models are more analytically tractable than random yield models. A popular sub-class of yield/capacity models (e.g., Baiman et al., 2000; Babich, 2006; Babich et al., 2007; Chaturvedi and Martínez-de-Albéniz, 2008; Gurnani and Shi, 2006; Swinney and Netessine, 2009; Yang et al., 2009a,b) is that with all-or-nothing yields, which corresponds to random number $y$ following a Bernoulli distribution: the buyer receives either the full order quantity or nothing at all. This type of yield model offers a fine compromise between tractability and fidelity, and is especially appropriate when modeling, for example, the loss of finished goods inventory due to recalls, or accidents or closures that put a supplier out of commission. Finally, supply cost risks have also been modeled in the study of decentralized supply risk management (Wan and Beil, 2008a). 


\section{Misalignment of Incentives}

Every paper we review in this chapter features misalignment of incentives between the buyers and suppliers. Thus, in subsequent sections misalignment of incentives plays a key role, but for expositional purposes we organize these sections around other ways in which decentralization affects supply risk management, namely, supplier competition, buyer competition and asymmetric information. However, even without those effects, misalignment of incentives still plays an important role in decentralized supply chains. For example, Zimmer (2002) studies a problem where the supplier might not invest in as much capacity as the buyer would like it to. In the paper's model, only a random fraction of the supplier's regular production capacity will be available when the buyer places an order, but the supplier can proactively procure a reliable premium capacity to increase its ability to meet the buyer's requirement. The author provides the insight that the buyer can coordinate the channel using a contract with either a penalty term for shortage or with a bonus term for on-time delivery.

\section{Competing Suppliers}

Supplier competition is possible when the buyer has several suppliers for the same product in its supply base, what we call "multi-sourcing." Competition among suppliers is good for the buyer because suppliers, keen on winning the buyer's business, are willing to accept smaller payments for their goods and services. Another benefit of multi-sourcing is risk-reduction through diversification, i.e., ordering from multiple suppliers simultaneously. Diversification and competition are two primary reasons for multi-sourcing in practice (see $\mathrm{Wu}$ and Choi 2005 and references therein). An important question that managers should consider is how their decisions affect both diversification and competition benefits. Intuitively, competition is most intense when the suppliers know that only one of them will be awarded the buyer's business, but in this case the buyer does not get any diversification benefits. Conversely, if the buyer orders from multiple suppliers for the sake of diversification, the suppliers have less incentive to compete. Is it possible to enjoy both types of benefits or do managers have to sacrifice one benefit for the other one? As we will see, the answer furnished by academic research is: "It depends." To understand this answer, in the following we will illustrate the benefits of diversification, define what we mean by supplier competition, discuss various forms and models of competition, and look at how competition and diversification interact with each other under different competition models.

\section{Diversification Benefits}

We begin by illustrating the benefits of risk-reduction through diversification. A buyer can make its supply more certain by ordering from two or more suppliers instead of one, provided the causes of 
supply disruptions are not perfectly correlated (recall our discussion in the Introduction on causes of disruptions). If the buyer's revenue is concave (exhibits a diminishing rate of returns) with respect to the supply quantity, or if its cost is convex (its marginal cost is increasing), the buyer favors a more certain supply quantity, as shown in the following example. (A side note: generally speaking, for diversification and risk management to have value, one does not need to assume that decision makers are risk-averse; as long as the objective function of the maximizer is concave or the objective function of the minimizer is convex in random variables of the problem, risk management is valuable; for more discussion on this see Froot et al. 1993.)

Example 1. Consider a buyer facing a demand of one unit for the next period. Assume the per-unit revenue for the product is $\$ 100$. There are two potential suppliers of the product with production costs of \$20 for supplier 1, and \$21 for supplier 2, and disruption probabilities of 0.4 for both suppliers. If a disruption happens, the entire order is lost, but if no disruption happens the buyer receives the full order. The buyer has to pay for the product up-front, but it has the power to set wholesale prices (and in particular it can set wholesale prices to be equal to the suppliers' production costs). The suppliers will accept the contract from the buyer as long as wholesale prices exceed or are equal to their respective production costs. Thus, in the optimal (for the buyer) contract the wholesale prices will be equal to the suppliers' production costs.

To highlight the benefits of diversification, first, assume that supplier disruptions are perfectly correlated. That is, if one supplier is down, the other one is down as well, and if one supplier is up, the other one is up as well. The buyer has no benefit from ordering from two suppliers and it will decide with which supplier to work by comparing the expected profits when working with each supplier. Of these two suppliers the buyer would choose to work with supplier 1, because it is cheaper, and the buyer's expected profit by ordering $z$ units is

$$
\text { Expected revenue }- \text { order cost }=0.6 \$ 100 \min (1, z)+0.4 \$ 100 \min (1,0)-\$ 20 z \text {. }
$$

The optimal choice for the order quantity $z=1$, leading to the expected profit of $\$ 40$.

In contrast, suppose that supplier disruptions are independent (this implies that the probability of both suppliers experiencing disruptions is $0.4 \cdot 0.4=0.16$, the probability that a given supplier delivers and the other one does not is $0.4 \cdot 0.6=0.24$, and the probability that both suppliers deliver is $0.6 \cdot 0.6=0.36)$. If the buyer orders from one supplier, then the expected profits remain the same as before (\$40 with supplier 1 and $\$ 39$ with supplier 2). However, if the buyer orders 1 unit from each supplier, it hedges its risk that one of the suppliers will not deliver and earns expected profit

$$
\begin{aligned}
\text { Expected revenue }- \text { order cost } & =\$ 100[0.36 \min (1,2)+0.24 \min (1,1)+0.24 \min (1,1) \\
& +0.16 \min (1,0)]-\$ 20 \cdot 1-\$ 21 \cdot 1=\$ 43 .
\end{aligned}
$$


The extra $\$ 3(=\$ 43-\$ 40)$ of the expected profit when ordering from both suppliers (relative to the best profit when ordering from one supplier only) is the benefit of diversification. This benefit decreases in the correlation between supplier disruptions (e.g. this benefit is zero when supplier disruptions are perfectly correlated), in accord with the intuition we have about diversification benefits in financial portfolios.

Having illustrated diversification benefits, we will now define supplier competition and discuss various supplier competition models.

\section{Forms and Models of Supplier Competition}

Supplier competition describes interactions among suppliers at the same horizontal level of the supply chain, with the property that the suppliers' interests are conflicting and the actions of one supplier can affect other suppliers' payoffs.

Supplier competition can take a number of forms. Babich et al. (2007) and Babich (2006) use a Bertrand competition model (Bertrand, 1883), where risky suppliers submit bids for the per-unit wholesale price of the product and the buyer selects which suppliers to work with and how much to order from each supplier, based on these bids and the joint distribution of supplier defaults. Babich et al. (2007) consider a one-period model, whereas Babich (2006) uses a multi-period model and recognizes that disparities in production lead times across suppliers allows the buyer to delay its ordering decision. More specifically, the buyer has a deferment option, which is "vulnerable," because the supplier with shorter lead time may experience a default before the buyer has a chance to order from it. Babich (2006) considers a multistage game, where the "slow" supplier submits a bid, then the buyer makes an ordering decision, then the "fast" supplier submits a bid, then the buyer makes another ordering decision. Thus, supplier competition is separated in time, which leads to interesting observations, as will be discussed below.

Instead of competing on price while keeping the supply risk parameters constant (as in Babich et al. 2007 and Babich 2006), suppliers can compete on "quality" by making investments in their production capabilities that affect their yield uncertainty. Federgruen and Yang (2009) study examples of quality competition, in which the supplier selects the mean and/or standard deviation of their production yield distribution. The buyer must satisfy a service level constraint (in contrast to the majority of other papers where shortage penalties are captured in the buyer's objective function) and the buyer's ordering decisions are determined by applying a Normal approximation to the total quantity received from the suppliers. Federgruen and Yang (2009) point out that these examples of supplier competition are special cases of generalized attraction models of competition, which appear in a number of other contexts, such as advertisement competition (Karnani, 1985) and fill-rate competition.

Suppliers need not make decisions beyond "participate/do not participate" in the business with 
the manufacturer in order for competition effects to be present. This kind of competition effect is highlighted in recent papers studying buyer-supplier relationships where the supplier has private information about its costs and supply risks. In Yang et al. (2009b) and Chaturvedi and Martínezde-Albéniz (2008), the buyer does not know the suppliers' types. Suppliers' types determine their production reliabilities and production costs. The buyer designs a menu of contracts to offer to the suppliers. In Chaturvedi and Martínez-de-Albéniz (2008) the supplier simply decides which of the buyer's contracts to accept (if any). In Yang et al. (2009b) the supplier decides which of the contracts to accept (if any) and then proceeds to make production decisions to fulfill the contract. If the buyer knew the suppliers' costs and reliabilities, it could extract the entire supply chain profit from the suppliers, leaving all suppliers with zero profits. But under asymmetric information, the suppliers can misrepresent their cost or reliability, permitting them to earn positive profit (see Section 6). Competition between suppliers in a two-supplier model arises when the buyer promises to select only one of the suppliers to fulfill the order, curbing suppliers' misrepresentation incentives and causing the suppliers to earn smaller profits. Thus, the presence of other suppliers affects profits in a way that is akin to the suppliers bidding against each other for the buyer's business.

One way to implement the bidding process is through auctions. Wan and Beil (2008a) and Wan and Beil (2008b) use auctions as a way of allocating orders to suppliers. For example, in Wan and Beil (2008a), suppliers privately know their own production cost. Furthermore, there is also a publicly known region-specific production cost, which depends on the geographic location of the supplier (e.g. US vs. Mexico vs. China). The buyer first designs its supply base (decides from which regions it would like to qualify suppliers) and then in each period, once the uncertainty about current region-specific costs have been realized, runs an auction to decide to whom to award the business.

What do we learn from these various competition models about managing supply risk?

\section{Is Positive Correlation Between Disruptions Bad for the Buyer?}

The first important insight is that competition and diversification can work against each other. The following simple illustrative example is based on Babich et al. (2007):

Example 2. Use the same data as in Example 1, but assume that the suppliers competitively choose wholesale prices.

When supplier disruptions are perfectly correlated, the buyer will never choose to work with more than one supplier. Instead, the buyer will order from the supplier who offers the lowest wholesale price. Thus, suppliers effectively compete in price for a single order from the buyer (this is the classical Bertrand competition model). Supplier 1 will win the order by offering a wholesale price just below \$21, a price impossible for Supplier 2 to profitably match. Supplier 1 will earn profit just short of \$1, supplier 2 will be priced out and earn zero profit, the buyer will order from supplier 1 
and will earn expected profit just above

$$
\text { Expected revenue }- \text { order cost }=0.6 \$ 100 \min (1,1)+0.4 \$ 100 \min (1,0)-\$ 21 \cdot 1=\$ 39 \text {. }
$$

Note that, compared with Example 1, the buyer's profit is $\$ 1$ less. However, $\$ 39$ is still much higher than $\$ 0$ profit the buyer would earn if supplier 1 were a monopolist. The reason for the buyer to keep most of its profit from Example 1 is competition between suppliers, which keeps the wholesale prices at \$21.

Next, suppose that the supplier disruptions are independent. Figure 1 illustrates the buyer's optimal decision as a function of the wholesale prices the suppliers bid. One can show (see Babich et. al. 2007) that the buyer is indifferent between diversifying and not diversifying if both suppliers offer wholesale prices $\$ 100 \cdot 0.24=\$ 24$ (recall that probability of a given supplier delivering and the other one failing is 0.24). Let's say the buyer would diversify. If both suppliers bid below \$24, the buyer will order from both suppliers (bottom left square in the figure). If supplier 2 bids higher than \$24 and supplier 1 bids less than supplier 2's bid, then only supplier 1 will receive an order (upper left part of the figure). Similarly, if supplier 1 bids higher than \$24 and supplier 2 underbids supplier 1, only supplier 2 will receive an order. No supplier who bids above $\$ 60$ will receive an order. We claim that \$24 is the equilibrium wholesale price in this simple economy. If one of the

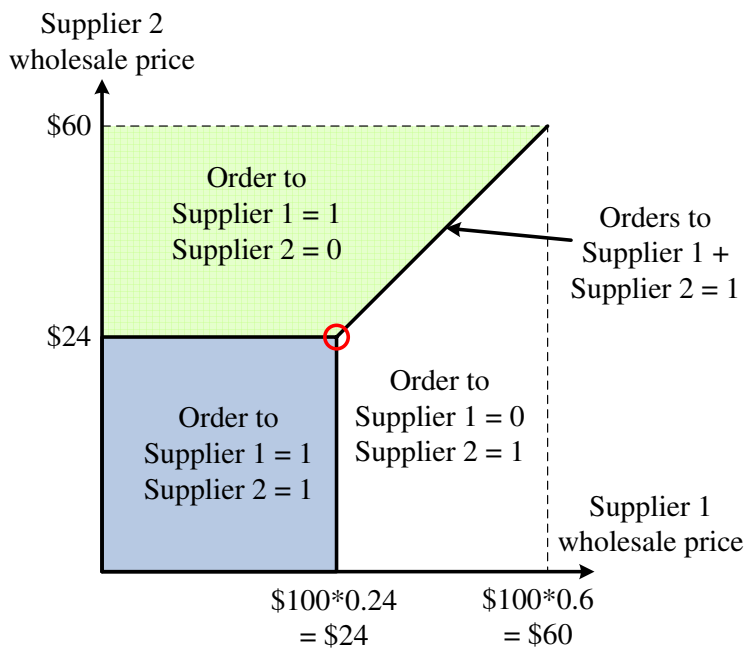

Figure 1: Buyer's order decisions as a function of supplier 1 and supplier 2 prices

suppliers lowers its price from \$24 to, say, \$23, that supplier will still receive the same order for one unit from the buyer, but will earn $\$ 1$ less in profit. Thus, no supplier would want to lower its price unilaterally. If one of the suppliers raises its price from \$24 to, say, \$25, the buyer will no longer order from that supplier, thus no supplier will want to raise its price unilaterally. With equilibrium wholesale prices of $\$ 24$, the profit of supplier 1 is $(\$ 24-\$ 20) \cdot 1=\$ 4$, the profit of 
supplier 2 is $(\$ 24-\$ 21) \cdot 1=\$ 3$, and the expected profit of the manufacturer is

$$
\begin{aligned}
\text { Expected revenue }- \text { order cost } & =\$ 100[0.36 \min (1,2)+0.24 \min (1,1)+0.24 \min (1,1) \\
& +0.16 \min (1,0)]-\$ 24 \cdot 1-\$ 24 \cdot 1=\$ 36 .
\end{aligned}
$$

First, observe that as the correlation between defaults decreased (from perfect to zero), contrary to what we have seen in Example 1, the buyer's expected profit decreased and the suppliers' profits increased. Second, the key to understanding why this has happened lies in the increase of the equilibrium wholesale prices from \$21 to \$24. This increase in prices is a manifestation of competition among suppliers, which does not exist in Example 1 or in other traditional "portfolio optimization" models.

An intuitive way to understand this example is to realize that the suppliers offer a product, which is identical in every respect, except for the states of nature in which this product will be delivered for the buyer. The correlation between defaults can be interpreted as the overlap between the states of nature where both suppliers deliver. If the supplier defaults are perfectly positively correlated, then the products from the two suppliers are perfect substitutes (the products will be available or not available in the same states of nature). In this case suppliers are engaged in classical Bertrand competition and the supplier with the lowest cost will charge a wholesale price equal to the second-lowest cost. Although there is no diversification benefit, the buyer enjoys low wholesale prices. If the supplier defaults are not perfectly correlated, the buyer enjoys some diversification benefits, but because the products are no longer perfect substitutes, the prices the suppliers charge are higher.

The idea that the states of nature where a supplier delivers are a part of the product's attributes is an important takeaway and it will be used again in our discussion of buyer competition in Section 5 .

\section{Buyer's Commitment to Supplier Competition}

In Example 2 the buyer plays a somewhat passive role. It does not control the mechanism by which prices are set and orders are allocated (i.e., the buyer does not design an auction or order allocation mechanism). The buyer decides its order quantities after receiving the suppliers' price bids, but does not have the power to commit a priori (before seeing the prices) to ordering from only one supplier. In Yang et al. (2009b) the buyer plays a more active role and, by designing the allocation mechanism (the rules governing the order quantities and fixed and variable payments), may commit to sole-sourcing. This power to commit proves beneficial for the buyer. The buyer may find it optimal to forego diversification in order to get better pricing from suppliers, who know they must compete harder to secure an order from the buyer. Thus, a key insight is that in a supply risk environment, where diversification and competition work against each other, the buyer 
may find it optimal to sole-source more in order to foster competition.

When the buyer foregoes diversification in order to enjoy the benefits of competition, consumers and the supply chain (as a whole) are worse off: without diversification, the quantity that the supply chain provides to consumers is reduced (where reduction should be understood in the stochastic ordering sense, as this quantity is a random variable).

\section{Buyer's Power to Design Contracts}

In Example 2 and Babich et al. (2007), correlation was a key driver of supplier competition and the buyer could not control the contract between it and the suppliers. In Yang et al. (2009b), the buyer can design the optimal mechanism for its interactions with the suppliers and correlation across suppliers' disruption risks does not increase competition, only the buyer's decision to sole-source does (but the buyer is more likely to sole-source as the correlation between supplier disruptions increases). Therefore, unlike Babich et al. (2007), in Yang et al. (2009b) the buyer prefers less correlated supplier disruptions, in order to make diversification-when it is used - more valuable.

The broader idea that the ability to control procurement mechanisms might affect the buyer's preference for competition, diversification, and risk correlation was first studied in Wan and Beil (2008a) in the framework of uncertainty about supply cost risks. Thus far we have discussed uncertain supply availability, where diversifying meant ordering from multiple suppliers. Another possibility is that supply availability is certain, but the buyer is concerned about cost risks. Even if the buyer commits to sole-sourcing, having suppliers in different regions bidding for the buyer's business can "diversify" the supply base. The following example, based on Wan and Beil (2008a), illustrates the tradeoff between competition and diversification benefits in such an environment. As in Wan and Beil (2008a), the example reveals how this tradeoff is affected by the buyer's ability to choose the contract allocation mechanism.

Example 3. Consider a buyer who will run a total-cost reverse-English auction (see explanation below) to award a contract to one of two suppliers. The buyer does not know the suppliers' true production costs $x_{1}$ and $x_{2}$, but does know how much it would cost the buyer to transport the goods from either supplier.

The total-cost reverse-English auction runs as follows: Suppliers take turns bidding prices, the buyer adds on the transportation costs, and bidders can view the resulting total cost bids in real time. The auction ends when no bidder is willing to lower their price bid further, and the lowest total-cost bidder is the winner and is paid its final price bid.

Suppose the buyer is located in Europe, and both suppliers are located in Taiwan (so the transportation cost from either supplier is the same, say \$4 per unit). Because transportation costs are the same for both suppliers, production cost alone determines the auction winner. Assume without loss of generality that $x_{1}=\$ 8<\$ 10=x_{2}$ (prices are per-unit); then supplier 1 wins at supplier 
2's dropout bid, \$10. The buyer's total per-unit cost (payment to winner plus transportation cost) is $\$ 10+\$ 4=\$ 14$.

Transportation costs differ from region to region and are subject to shocks. ${ }^{3}$ Intuitively, choosing suppliers in different regions mitigates the buyer's exposure to the risk of high transportation costs. To see how a more diverse supply base would affect the buyer's total costs, assume the same numbers as before, except suppose supplier 1 is located in Brazil from which the transportation cost is \$1 per unit. Now supplier 1's total (production plus transportation) cost is $\$ 8+\$ 1=\$ 9$, while supplier 2's total cost is still $\$ 10+\$ 4=\$ 14$. Supplier 2 will drop out of the auction with a price bid of $\$ 10$, translating to a total cost bid of \$14. Supplier 1 will defeat supplier 2 by offering a price just below $\$ 13$. The buyer's total per-unit cost (payment to winner plus transportation cost) is $\$ 13+\$ 1=\$ 14$.

Note that, despite the diversified supply base, the buyer incurs the same total cost as before. Although the buyer enjoys cheaper transportation costs (\$1 instead of \$4), this is offset by supplier 1 charging a higher per-unit price (\$13 instead of \$10). When the buyer must rely solely on supplier competition for price concessions, diversifying the supply base (having suppliers in different regions) does not necessarily help the buyer. In fact, one can show that it actually makes the buyer worse off by increasing the buyer's cost risks: Whenever either region experiences a high transportation cost, the supplier in the other region can simply raise its price and enjoy high windfall profits at the expense of the buyer.

Again, we see that the buyer may prefer less diversification (more correlated supplier costs) in order to foster more competition. The key feature for Example 3 is that the buyer must rely solely on supplier competition for price concessions. As Wan and Beil (2008a) explain, if the buyer can institute other techniques to limit suppliers' windfall profit-taking (such as optimal auction rules admitting only part of a supplier's regional cost advantage over its competitors), then the buyer can retain much more of the diversification benefits that arise from having suppliers in different regions, and such buyers prefer to diversify (prefer less correlated supplier costs).

Thus, our next key insight is that buyers with greater power to design contract allocation mechanisms find diversification more attractive. To put this insight in the context of supply availability risks, note that in Example 1 the buyer had the power to make take-it-or-leave-it offers and preferred to diversify when the suppliers' disruption risks were independent. In contrast, in Example 2 the buyer relied on competition for price concessions, and would have preferred to commit to sole-sourcing (had it been possible to do so).

\section{Can a Buyer Have Both Competition and Diversification Benefits?}

We see from Examples 2 and 3 that the buyer might prefer suppliers that have more correlated risks (on either costs or supply disruptions). While seemingly counter-intuitive, this insight is based on

\footnotetext{
${ }^{3}$ For example, in 2008 insurance premiums on Asia to Europe ocean transport increased tenfold, as ships passing through the Suez Canal faced piracy threats off the Somali coast (Costello, 2008).
} 
the fact that more correlated suppliers compete harder with each other and are less able to use high pricing to devour the benefits of diversification. An interesting corollary is that the buyer might be able to enjoy both the benefits of competition and diversification (as Babich et al., 2007 and Wan and Beil, 2008a point out) if the buyer has, say, four suppliers and "partially diversifies." That is, divide suppliers into clusters (e.g. geographically) of two or more suppliers each. Within each cluster the disruptions must be highly correlated (e.g. all Taiwanese LCD suppliers are exposed to the same natural disaster, political instability, country-wide financial crisis risks), so that there is a fierce inter-cluster competition among suppliers. At the same time, correlation of disruptions across clusters must be low, so that by ordering from suppliers from different clusters (e.g. from Taiwan and the US), the buyer can enjoy the benefits of diversification.

\section{Weakening Supplier Competition by Separating Decisions in Time}

Competition among suppliers depends on products they offer (i.e. the degree of product substitutability), the correlation among suppliers (i.e. supplier disruptions can be thought of as a product attribute), as well as the timing of the bids. In the context of supply disruptions, suppliers can weaken competition if their bids and the buyer's orders are spread over time, which is another managerial takeaway. Recall that Babich (2006) considers a multistage game between the buyer and two suppliers: one supplier with a short production lead time and the other supplier with a long production lead time. In this game, the "slow" supplier submits a bid, then the buyer makes an ordering decision, followed by the "fast" supplier submitting a bid, and the buyer making another ordering decision. When suppliers have the power to set wholesale prices, this order deferment by the buyer weakens competition between suppliers, to their advantage. Unlike results in Babich et al. (2007) discussed above, in this paper the buyer no longer prefers perfect correlation between supplier disruptions. Instead, it earns the highest profit at intermediate correlation values. Another interesting observation arising from order deferment is that, when the buyer holds all of the bargaining power (sets wholesale prices), a supplier might suffer if it reduces its lead time. Specifically, under certain conditions, if both suppliers have the same lead time, they would both receive orders from the buyer. But if one of the suppliers reduces its lead time the buyer would treat that supplier as a backup and order from it only if the slower supplier had a disruption.

\section{Multiplicity of Equilibria}

One consideration to keep in mind when interpreting the results from game theoretic models is that there could be multiple equilibria. This observation is important for managers because (1) using game theoretic models for decision making is difficult if one does not know which of the equilibria will be realized in practice; (2) benefits to the system could be significant if there is a way of affecting which equilibria is realized. Illustrating this point in the context of supplier 
competition, Federgruen and Yang (2009) show that, in general, their competition models have multiple equilibria. Furthermore, they show that different equilibria could be quite far from each other from the social welfare perspective. However, their game model is log-supermodular, which allows them to derive comparative statics for some of the equilibria. They show that if some quality standards can be imposed by the government or other outside entity, the highly undesirable equilibria can be eliminated.

\section{Section Summary}

The key insights and main takeaways from this section are as follows. First, as academic researchers and practitioners know, there are benefits of diversifying the supply base due to supply risk reduction and these benefits increase as the correlation among random events decreases. Next, decreasing correlation can be thought of as decreasing substitutability among products. Therefore, if the suppliers compete, as correlation decreases, the competition becomes less intense. Consequently, buyers may actually prefer suppliers with highly correlated disruptions, because such suppliers compete the most. A buyer who commits to sole-sourcing encourages competition, but abandons diversification. In general, the more control the buyer has over the design of the mechanism that governs its interactions with suppliers, the less the buyer has to rely on competition among suppliers to keep its procurements cost in check and the more the buyer enjoys diversification benefits. Finally, when working with multiple suppliers the buyer may be able to capture both competition and diversification benefits by breaking suppliers into clusters with fierce inter-cluster competition and diversification across clusters.

\section{Competing Manufacturers}

So far, in our discussion of supply risk management we have ignored the strategic interactions among buyers. This omission is innocuous for firms in mature industries, comprised of many small firms, where each one is a price-taker. However, there are many industries with only a few dominant firms. The interactions among such firms (e.g. Boeing and Airbus, Pfizer and Eli Lilly) are better described by oligopoly models, where actions of one firm affect other firms in the industry. In this section we will address two questions: (1) How does oligopolistic competition affect the supply risk management actions of buyers? (2) How do supply risk and supply risk management affect the oligopolistic competition among buyers?

The primary sources of insights for this section are Deo and Corbett (2008), Tang and Kouvelis (2009), and Wadecki and Babich (2009). In all of these papers, the planning horizon has two stages. In the first stage buyers either (i) decide whether to enter the market (Deo and Corbett, 2008), or (ii) select the structure of the supply network (Tang and Kouvelis, 2009), or (iii) provide suppliers with financial subsidies (Wadecki and Babich, 2009). In the second stage, buyers compete. For the 
second stage, all three papers rely on the Cournot (1838) model $^{4}$ to capture competitive interactions among firms in the final product market. Deo and Corbett (2008) and Tang and Kouvelis (2009) model supply uncertainty as proportional random yield, which affects the output in the second stage of the model (i.e. when a manufacturer decides to produce $\bar{q}$ units, it successfully produces only $q=y \bar{q}$ ). In Wadecki and Babich (2009) supply uncertainty is modeled via Bernoulli random variables and supply uncertainty is resolved in the first stage, before buyers engage each other in the final product market.

We begin with the discussion of Cournot competition game of the second stage.

\section{Supply Risk and Cournot Competition}

To help us appreciate the effect of supply risk on competition among firms, it is useful to recall insights from the classical Cournot (1838) model, to be used as a benchmark for subsequent results. There are $N$ firms who compete by selecting quantities $q_{i}$ they send to the market. If the total quantity in the market is $Q=\sum q_{i}$, the market price for the product is $p=a-b Q$. Firms incur unit production cost $c$. The Cournot equilibrium quantities, total output to the market, prices, and profits are $q^{e}=\frac{a-c}{(N+1) b}, Q^{e}=\frac{(a-c) N}{(N+1) b}, p^{e}=\frac{a+c N}{N+1}$, and $\pi^{e}=\frac{(a-c)^{2}}{(N+1)^{2} b}$, respectively. To capture the consequences of competition in this classical model, we compare these equilibrium quantities with the optimal quantities in the centralized system. If all $N$ firms were controlled by one decision maker, then effectively there is only one firm, $N=1$. Its optimal monopolist production quantity (equal to total output to the market), resulting price, and optimal profit are $q^{m}=Q^{m}=\frac{a-c}{2 b}$, $p^{m}=\frac{a+c}{2}$, and $\pi^{m}=\frac{(a-c)^{2}}{4 b}$, respectively. Observe that the competitive system oversupplies, $Q^{e}=\frac{(a-c) N}{(N+1) b}>\frac{a-c}{2 b}=Q^{m}$, which lowers the resulting market prices $p^{e}=\frac{a+c N}{N+1}<\frac{a+c}{2}=p^{m}$.

Next let us introduce supply risk in the form of random yield to the Cournot model, by assuming that the quantity that buyer $i$ sends to the market is $q_{i}=y_{i} \bar{q}_{i}$, where $\bar{q}_{i}$ is the quantity that buyer $i$ orders from its risky supplier. Assume that yields, $\left\{y_{i}\right\}_{i=1}^{N}$, are independent, identically distributed random variables, with mean $\mu$, standard deviation $\sigma$, and coefficient of variation $\delta=\frac{\sigma}{\mu}$. Let $d$ be the cost per unit of delivered product. In addition, assume that $o$ is cost per unit of product ordered. One can compute the equilibrium order quantities, expected total market output, expected prices, and expected profits to be $\bar{q}^{e}=\frac{a-(o / \mu+d)}{\mu b\left(N+1+2 \delta^{2}\right)}, E Q^{e}=\frac{[a-(o / \mu+d)] N}{b\left(N+1+2 \delta^{2}\right)}, E p^{e}=a-b E Q^{e}$, and $E \pi^{e}=\frac{[a-(o / \mu+d)]^{2}\left(1+\delta^{2}\right)}{b\left(N+1+2 \delta^{2}\right)^{2}}$. To allow "apples to apples" comparisons with the classical Cournot model, we require that the cost per unit of product sent to the market in the model with supply risk, $o / \mu+d$, equals the equivalent cost $c$ in the Cournot model. With this restriction, we observe that when yields $y_{i} \equiv 1$ (no supply risk, i.e. $\delta=0, \mu=1$ ), then the equilibrium quantities in the model with supply risk are equal to the equilibrium quantities in the classical Cournot model.

Comparing equilibrium quantities of the Cournot model and the Cournot model with supply

\footnotetext{
${ }^{4}$ See Moorthy (1985) for applications of game theory to model competition: price and quantity competition, entry games, and dynamic oligopoly games.
} 
risk, Deo and Corbett (2008) document an important effect of supply risk: with supply risk both the quantity ordered by the buyers and the total expected quantity sent to the market decrease. This reduction has significant societal ramification and Deo and Corbett (2008) argue that it might be the culprit of the chronic flu vaccine shortage in the United States. If the coefficient of variation, $\delta$, is high enough, then the order quantity under supply risk could be even smaller than the optimal order quantity of the monopolist buyer without supply risk.

We will continue the discussion of results in Deo and Corbett (2008) shortly, but before that it is important to note an important insight from Tang and Kouvelis (2009) on the role of competition for a fixed number of buyers $N$. Tang and Kouvelis (2009) consider a Cournot game between $N=2$ buyers, similar to Deo and Corbett (2008), but allow supplier random yields to be correlated. As the correlation between random yields increases, order quantities decrease and prices increase, but buyers' profits decrease. Intuitively, similar to what we have learnt in Section 4 on competing suppliers, buyer' products are differentiated by the states of nature when those products are available (i.e. states of nature where suppliers deliver). Greater correlation implies less differentiation and more fierce competition between buyers. Buyers that are eager to avoid competition should try to order from suppliers whose yields are uncorrelated. In particular, Tang and Kouvelis (2009) conclude that buyers, if feasible, should not order from the same supplier (for this would introduce perfect correlation).

In this subsection we have discussed the effects of supply risk on the Cournot sub-game in the second stage of models in Deo and Corbett (2008) and Tang and Kouvelis (2009). Next we will study the games that happen in the first stage: market-entry competition, choice of supply chain structure, and financial subsidies games.

\section{Market-Entry Competition and Supply Risk}

This subsection discusses insights from the market-entry competition game that determines the number of buyers $N$ to compete in the second-stage Cournot game of Deo and Corbett (2008). To ensure that $N$ is finite, Deo and Corbett (2008) assume that each firm entering the market in the first stage pays a fixed entry fee $f$. They find that the effect of yield uncertainty on the number of entrants in equilibrium depends on how attractive the market is for the entrants. If the market size is relatively small, there will be fewer entrants in the model with supply risk compared to the model without supply risk. Interestingly, if the market size is large, limited supply risk could result in greater numbers of entrants in equilibrium. But even if the total number of entrants increases, the production of each of them decreases so much that the expected output in the model with supply risk is lower than the output without supply risk. Thus, even when the number of firms in the flu vaccine industry is determined endogenously, the effect of supply risk is to reduce the availability of the vaccine. 
Deo and Corbett (2008) also consider a model where entry decisions are controlled by a central planner, but production quantities are determined competitively by the firms. The authors find that if the supply uncertainty is above a certain threshold, then the equilibrium number of firms in the market-entry game will be less than what the central planner would have chosen. Thus, a deregulated market, where firms themselves decide whether or not to start producing vaccine, could lead to greater vaccine supply risk, because with fewer firms there is less diversification.

\section{Supply Risk and Supply Chain Structure}

Tang and Kouvelis (2009) assume that the number of buyers is fixed, $N=2$, but in the first stage of the model, the buyers decide whether to sole source or dual source and with which supplier(s). First, the authors consider the model where only two suppliers are available, as illustrated in Figure 2, and characterize the equilibrium choice of sourcing strategy.
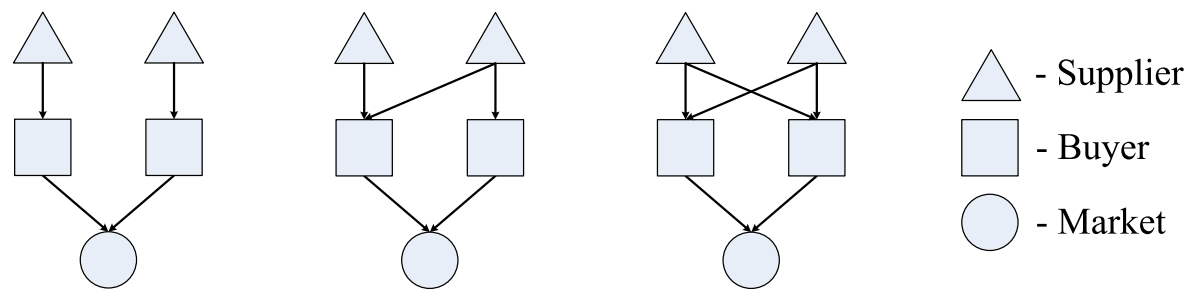

Figure 2: Supply chain structures with two suppliers in Tang and Kouvelis (2009)

In this setting, the first tradeoff a buyer faces is between the fixed cost of working with an extra supplier and benefits of diversification. Higher fixed cost retards diversification. Lower correlation between suppliers' random yields encourages diversification. This first tradeoff is present in every model with a dual-sourcing decision. The second tradeoff has features unique to problems with buyer competition: a buyer is choosing between costs of buyer competition and benefits of diversification. To reduce costs of competition, the buyers try to differentiate from each other. In particular, they would like to order from different suppliers. With only two suppliers available, the buyers end up choosing between sole-sourcing from different suppliers (thus losing diversification benefits, but reducing costs of competition) and dual-sourcing from the same two suppliers (thus gaining diversification benefits, but increasing costs of competition).

Tang and Kouvelis (2009) also consider a model with two sets of two suppliers. One could interpret these sets as geographically-separated supply bases. Therefore, the correlation of yields between sets is zero, while correlation of yields within sets could be positive (or negative). The insights derived from the two tradeoffs described above continue to hold. 


\section{Subsidies to Suppliers in the Presence of Buyer Competition}

Wadecki and Babich (2009) and Babich (2009) consider decisions of buyers to subsidize suppliers in the first stage of a planning horizon. These papers are motivated by the idea that ordering and payment policies of a buyer affect its supplier's financial viability, which in turn affects the supplier's ability to offer capacity to the buyer. These papers are inspired by numerous examples from the US automotive industry, which has witnessed bankruptcies of not only automotive suppliers but also large manufacturers (both Chrysler and General Motors declared bankruptcy in 2009).

As Babich (2009) discusses, suppliers in or close to bankruptcy could face labor strikes, lose key personnel, reduce efforts in quality control, or forego capacity investments. Creditors of bankrupt suppliers may try to "hold up" buyers, taking advantage of the critical role many suppliers play for buyers. A well-known example of a "hold-up" is UPF Thompson vs. Land Rover, discussed in the Introduction. A very recent example of a supplier's bankruptcy affecting its operational performance is the case of Chrysler and Plastech. After Plastech filed for bankruptcy in 2008, it stopped shipping plastic moldings to Chrysler and Chrysler had to shut down four plants.

The use of financial subsidies, without buyer competition, was studied by Babich (2009), who solves a dynamic procurement/subsidy problem and proposes conditions that allow procurement decisions to be made independently from subsidy decisions. Wadecki and Babich (2009) solve the one-period variant of the problem in Babich (2009), but with buyer competition. They consider a model with $N=2$ buyers and compare four supply chain structures (see Figure 3): (1) buyers do not compete and each has its own dedicated supplier, (2) buyers do not compete, but they share the same supplier, (3) buyers compete and each has its own dedicated supplier, and (4) buyers compete and share a supplier.

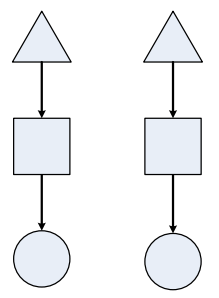

Supply chain structure 1

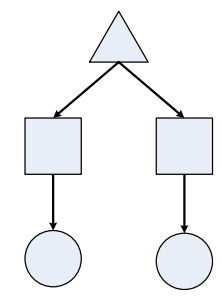

Supply chain structure 2

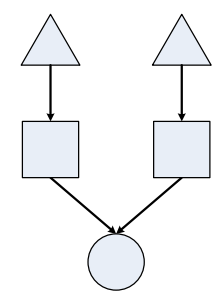

Supply chain structure 3

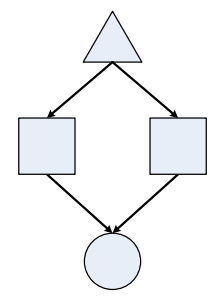

Supply chain structure 4

Figure 3: Four supply chain structures considered in Wadecki and Babich (2009).

With supply chain structure 1, when deciding how much to pay its supplier, each buyer faces a key tradeoff between increasing the probability that the supplier will be available to provide products in the second stage and the costs of raising money for a subsidy (as in Babich, 2009).

The immediate effect of competition (supply chain structure 3) is that (unless the market size increases), subsidies to the suppliers decrease, because buyers now earn smaller profits by having to share the market and, therefore, are less keen to ensure that the suppliers stay in business. 
According to Tang and Kouvelis (2009), buyers should always prefer supply chain structure 3 to supply chain structure 4 , because by ordering from different suppliers, buyers can achieve differentiation and reduce competition. Wadecki and Babich (2009) suggest that sometimes supply chain structure 4 might be preferable, due to a cross-subsidy effect-the shared supplier becomes very reliable because it receives subsidies from two buyers. Under supply chain structure 4, although each buyer pays less than it would to a dedicated supplier, the total payment the supplier receives is greater in equilibrium. For example, because of the cross-subsidy effect, supply chain structure 2 always dominates supply chain structure 1 for the buyers.

Wadecki and Babich (2009) offer another interpretation of the competition effect. Supply chain structure 3 might be preferable to supply chain structure 4 due to the windfall profits effect: when working with dedicated suppliers, buyers are betting on the other supplier going out of business and leaving the buyer to enjoy monopolist windfall profits. When the market size is large, the expected benefits of the windfall profits are greater than the cross-subsidy benefits. Thus, buyers prefer a fragmented supplier industry.

\section{Section Summary}

The main insights from this section are as follows. Supply risk results in lower Cournot order quantities. The number of buyers who decide to enter the market could increase or decrease under supply risk, but the net effect of supply risk is that the expected quantity of products sold in the market always decreases, sometimes very drastically. Thus, one explanation for flu vaccine shortages in the US could be the intrinsic uncertainty in the vaccine production process. Competition among buyers alters their risk management strategies. Without competition, when considering diversification buyers weigh fixed costs of working with an extra supplier against diversification benefits. Under competition, buyers try to differentiate from each other, and sometimes they would rather forego diversification than order from the same set of suppliers. Ordering from the same supplier is not always bad, however. A supplier who receives multiple orders is more viable financially and, therefore, a more reliable supply source. Whether buyers prefer to have a few large shared suppliers or many small dedicated suppliers depends on the tradeoff between cross-subsidy and competition effects.

\section{Asymmetric Information}

As discussed in the Introduction, in many settings suppliers are privileged with private information, for example, about the cost or reliability of their production or quality of items produced. Private information can affect the decisions and profits of the supply chain. In this section we discuss how a buyer facing supply disruption risks can (1) understand how asymmetric information affects the incentives of self-interested suppliers, (2) apply countermeasures against these incentives, and 
(3) understand when such countermeasures can change how the supply chain deploys traditional supply-risk management tools (e.g. backup production).

\section{Supplier Misrepresentation Incentives}

Decisions are governed by incentives, and thus we begin this section by studying how suppliers' incentives are affected by their private information.

Scenario 1 - private information about production cost. Consider a buyer who sole-sources from a supplier with private information about its true production cost (which could be a function of its capacity utilization, order backlog, inventory level, etc.). How would the buyer figure out how much to offer to pay the supplier for production? Clearly the buyer could not ask the supplier to produce at a loss, but what is the supplier's break-even cost?

One can easily imagine that the supplier in Scenario 1 has an incentive to claim that its production is very costly, in an attempt to inflate the payment from the buyer. In other words, lower cost is of course better, but suppliers actually have an incentive to pretend to be worse (higher cost) than they actually are. The incentives in Scenario 1 are obvious, but incentives can also manifest themselves in less-obvious ways. Consider the following scenario.

Scenario 2 - private information about supply reliability. Suppose that a supplier has private information about its reliability, say the probability that it can successfully deliver the items ordered by the buyer. For example, unsuccessful delivery could correspond to items that are defective or destroyed in a factory fire. Casual intuition might suggest that a supplier would always have an incentive to appear more reliable, but as with Scenario 1 the opposite is true.

Suppose the supplier has to incur up-front expenses when working on the buyer's order and the buyer pays the supplier only when the supplier delivers. For the same contract from the buyer, a more reliable supplier earns higher expected profit. Therefore, to ensure that a supplier breaks even, the buyer has to pay more to a less reliable supplier. This creates an incentive for suppliers to pretend to be less reliable than they are - in other words, suppliers again can have an incentive to pretend to be worse than they actually are.

In summary, self-interested suppliers can utilize their private information in an attempt to secure more favorable contracting terms from the buyer. In the next subsection we discuss countermeasures the buyer can use to manage this.

\section{Managing Supplier Misrepresentation Incentives}

In this subsection we discuss a spectrum of approaches, applicable in the context of supply disruptions, to control supplier incentives to misrepresent their private information.

Take it or leave it offers. When the buyer faces a single supplier, the optimal negotiation format chosen by the buyer often involves making a take-it-or-leave-it offer to the supplier. By definition, 
when the buyer makes a take-it-or-leave-it offer it gives the supplier an ultimatum: accept my terms, or I walk away. This heavy-handed approach gives the supplier no opportunity to counter-offer and seek more favorable terms, thereby limiting the supplier's ability to leverage its private information. When contracting terms involve multiple dimensions (e.g., payment and non-delivery penalty), the buyer often finds it desirable to simultaneously offer the supplier multiple take-it-or-leave-it offers (e.g., high payment/high penalty or low payment/low penalty), and let the supplier select which offer it most prefers from the offer "menu."

Supplier competition. Making a take-it-or-leave-it offer requires the buyer to credibly commit to not renegotiate with the supplier should the supplier choose to reject the buyer's offer (or menu of offers). The supplier, however, might not believe the buyer would really walk away from the deal. Without a credible walk-away threat, the buyer's take-it-or-leave-it offer is meaningless. When the buyer does not have the power or credibility to make such walk-away threats, supplier competition is an alternative countermeasure against supplier misrepresentation incentives. Regardless of the buyer's lack of supply chain power, a bid from one supplier can be used as a "stick" to gain concessions from other suppliers. Auctions have been used for millennia to buy and sell items and are a classic way to harness competition in a negotiation. The common process of putting a supply contract up for bid constitutes a "reverse" auction whereby bids are solicited from suppliers and the contract winner(s) and payment(s) are determined. When bidding, suppliers must trade off their desire for a large profit (e.g., asking a high price) against the chance that by being too greedy they might win less - or possibly none - of the buyer's business.

Power to design auction mechanisms. When the buyer has multiple suppliers and holds the power to make take-it-or-leave-it offers, it can leverage supplier competition and the ability to design a menu of offers. For instance, the buyer could employ a reverse auction in conjunction with a reserve price. The reserve price imposes an upper bound on the amount the buyer is willing to pay for the contract and thereby caps the profit of the winning supplier. More generally, supplier profits can be reduced further when the buyer has the power to dictate any kind of take-it-or-leaveit negotiation rules, for example, rules that favor weaker suppliers over stronger suppliers in order to enhance competition.

Other trading mechanisms. In general, the buyer's desire to manage supplier misrepresentation incentives can lead it to strategically employ take-it-or-leave-it offers, competition, or specific auction mechanisms. However, there may be reasons that the buyer cannot influence the choice of the trading mechanism, for example, due to historical precedence. It is therefore worthwhile to note the possibility of other trading mechanisms - for instance, a buyer and a supplier might make alternating counter offers ("bargain") until reaching an agreement, and thereby split the supply chain profits in some exogenously defined way.

In the extant literature on decentralized supply risk management in the presence of asymmetric information, all of these various approaches are studied. Lim (1997), Yang et al. (2009a), Yang et 
al. (2009b), Chaturvedi and Martínez-de-Albéniz (2008), and Wan and Beil (2008a) all assume a strong buyer able to make take-it-or-leave-it offers. Wan and Beil (2008a) examines a spectrum of buyers, ranging from those able to make take-it-or-leave-it offers to those who must rely solely on competition for price concessions. Gurnani and Shi (2006) examine a bargaining setting.

\section{Effect of Asymmetric Information on Supply Risk Tools}

Countermeasures to mitigate supplier incentives are not deployed in a vacuum. For better or worse, they often affect how the supply chain operates. For example, when the buyer makes take-it-or-leave-it offers to suppliers, there is a chance that suppliers will reject the offer, leaving the buyer high and dry. In the context of supply risk, an important consideration is how such countermeasures affect the buyer's use of supply risk management tools, such as: backup production at the buyer, backup production at the supplier, nonperformance penalties, quality screening, supplier qualification screening, dual sourcing, supply base diversification, etc. We explore these issues in this subsection.

Supplier/buyer backup production. As discussed in the Introduction, it is plausible that the supplier or buyer could utilize backup production in the event of a supply disruption. Yang et al. (2009a) study such a setting in which the buyer faces a single supplier possessing private information about its reliability. It is found that when the supplier's reliability is its private information, the buyer is less likely to use the backup production option of the supplier, but more likely to rely on its own (more costly) backup option. Why does asymmetric information about supply risk cause the buyer to utilize supplier backup production less? If the supplier is asked to use its backup production in the event of a disruption, the cost differential between a more reliable supplier and a less reliable supplier grows further, because the latter is more likely to suffer a disruption and, hence, more likely to incur the cost of using backup production. Consonant with the discussion above for Scenario 2, this widening of the cost gap increases the more reliable supplier's incentive to misrepresent itself. Thus, the buyer may choose to forego the supplier backup production option to reduce the high-reliability supplier's misrepresentation incentive.

Supplier diversification. Supplier diversification is another tool that the buyer can use to mitigate supply risks. Yang et al. (2009b) study a buyer facing two suppliers that are each subject to random supply disruption. To increase the chance of delivery the buyer can diversify, that is, contract with both suppliers simultaneously. Each supplier's reliability (probability of disruption) is their own private information. The buyer sets payment-on-delivery terms to ensure that the suppliers have an incentive to deliver. Following the theme of this section, such contingent payments create an incentive for suppliers to misrepresent their reliability. Because asymmetric information effectively makes it more costly to do business with suppliers, diversification becomes more costly and hence the buyer utilizes diversification less. Chaturvedi and Martínez-de-Albéniz (2008) show a similar shift away from diversification (caused by asymmetric information about production costs). 
Supplier qualification screening. As described in the Introduction, buyers often rely on supplier qualification screening to reduce supplier nonperformance risks. Since suppliers have private information about their costs, buyers often use auctions to mitigate suppliers' incentives to inflate their prices. In practice, qualification screening typically precedes the auction, meaning that the buyer wastes time and money qualifying suppliers who wind up losing the auction. Wan and Beil (2008a) find that this practice can be improved upon by postponing all or part of the supplier qualification screening until after the auction. In particular, when qualification is costly, reducing qualification costs through judicious post-qualification can more than offset expected increases in the contracting costs resulting from higher prices in the auction (which arise since postponing qualification screening means that some attractive auction bids might be disqualified).

Product inspections. Defective parts are costly for the supply chain, requiring either rework if they are discovered by the buyer, or - even worse - warranty and goodwill costs if they are discovered by the end user (the buyer's customer). Lim (1997) focuses on a buyer unsure of the quality level of her supplier, namely the probability that any given part from the supplier will be defective. While the buyer would like to share quality-related costs with the supplier, the asymmetric information makes it difficult for the buyer to decide how much to penalize the supplier for defects caught at inspection and in the field. Intuitively, high penalties make the contract very unattractive to an unreliable supplier. Lim (1997) finds that to ensure the contract is attractive to any supplier type - even the least reliable suppliers - the buyer winds up absorbing more of the quality-related costs.

In a similar vein, Baiman et al. (2000) study a situation where the supplier's effort to reduce the fraction of defective units in production or the buyer's effort to inspect incoming units may not be publicly observed and thus may not be contractible. The authors find that the optimal channel profit can still be obtained if the buyer and supplier can contract upon one of the following three sets of information: (a) the supplier's defect prevention effort; (b) the buyer's quality inspection effort and product failures reported by either the buyer or the customer; and (c) product failures reported by both the buyer and the customer.

Nondelivery penalties. Yang et al. (2009a) examine nondelivery penalties and whether or not the buyer wishes to set the penalty high enough to induce the supplier to use its backup production option in the event of a supply disruption. Nondelivery penalties also feature prominently in Gurnani and Shi (2006), where a buyer and supplier have differing estimates of the supplier's reliability. While the buyer knows the supplier's reliability self-estimate and the supplier knows the buyer's estimate of the supplier's reliability, neither the buyer nor supplier knows the true reliability for sure. Unlike the papers described above where the buyer essentially seeks to discover information held privately by the supplier, in Gurnani and Shi (2006) the buyer's beliefs about reliability are not affected by knowing the supplier's self-estimate. Depending on whether the buyer's estimate is larger or smaller than the supplier's, the paper suggests employing contract terms incorporating 
either downpayment or nondelivery penalty.

Value of tools under asymmetric information. Thus far we have seen that asymmetric information effectively makes it more expensive to use supplier backup production, diversification, and supplier qualification screening. However, this does not mean that such tools are no longer valuable, as we discuss next.

Yang et al. (2009a) find that asymmetric information about supplier reliability causes supplier backup production to be used less, but they also show that the value of supplier backup production for the buyer is not necessarily larger when it perfectly knows the supplier's reliability. In particular, adding a cheap backup production option diminishes the supplier's benefit of misrepresenting its reliability (since reliability overall becomes less of a concern). This incentive reduction provides an extra benefit which does not exist when information is symmetric.

Although Yang et al. (2009b) find that asymmetric information about supplier reliability causes the buyer to utilize diversification less, they also show that having a dual sourcing option (i.e., having two potential suppliers) is very valuable for the manufacturer even if she does not use this option to diversify her supply. Merely having two suppliers allows the buyer to play one supplier against the other to receive better pricing, a competition benefit which is absent when the buyer has perfect information about the suppliers.

In Wan and Beil (2008a), supplier qualification screening is still imperative - a buyer would be loathe to enter into an important contract with a supplier until knowing the supplier has passed qualification screening. While qualification screening is still extremely valuable, the manner in which it is used changes due to asymmetric information. In particular, post-qualification can be part of an optimally balanced supplier qualification strategy, which may become ever more important as supply sources globalize and asymmetry of information worsens.

\section{Section Summary}

Self-interested suppliers can misrepresent their private information to the buyer, for example, by misreporting their reliability. The desire for more favorable contract terms (e.g., a higher price or lower nonperformance penalties) can provide suppliers an incentive to do so. To mitigate this incentive while managing supply risks in a decentralized supply chain, the buyer can deploy optimally designed take-it-or-leave-it-offers, supplier competition, or both. These countermeasures affect - and are affected by - the supply risk tools available to the buyer. Countermeasures that control incentives by reducing the costliness of doing business with any supplier type tend to cause the buyer to lessen its use of costly risk mitigation measures, as seen for supplier backup production and diversification. Likewise, the tools themselves can change how the buyer deploys countermeasures. For instance, a buyer with very cheap backup production (at the buyer or supplier) worries little about reliability and hence need not worry greatly about imposing stringent countermeasures against supplier incentives, and a buyer with a dual sourcing option might choose to use it to re- 
duce incentives via competition (taking cost-reduction benefits) rather than diversification (taking supply-risk-reduction benefits).

\section{Conclusions}

Research on decentralized supply risk management is relatively new, yet it has already produced a number of interesting, surprising, and salient insights. We believe that more exciting findings lie ahead in this field, and to conclude this chapter we will discuss several promising research directions that have yet to be explored.

In traditional risk management, statistical data analysis is a crucial step when forming practical recommendations. Yet the papers discussed in this chapter are based primarily on theoretical analysis. We think that an important future research direction is to adopt a more data-driven approach. Such data-driven research can be in the form of empirical research, which would take advantage of increasing amounts of data about the causes, durations and costs of supply disruptions (e.g., Hendricks and Singhal, 2003) to validate theoretical recommendations and to quantify the value of various tools for decentralized risk management. Alternatively, data-driven research can take the form of experimental studies, which could explore the effects of managerial attitudes toward supply risk (e.g., Schweitzer and Cachon, 2000) and the interactions between multiple players in decentralized systems in experimental settings (see Trading Agent Competition, http: //www.sics.se/tac).

As was highlighted in this chapter, a key form of decentralized supply risk management is information asymmetry, for example, suppliers having private information about their costs and reliabilities, or buyers having better information about the market value of their products. A promising direction for future research is to utilize richer models of beliefs held by parties regarding others' private information. Buyers' beliefs about suppliers' reliabilities may differ from suppliers' beliefs about each other. Such differences in beliefs raise questions about who in the supply chain has higher-quality information, and what is the best way to delegate supply-chain decisions (e.g., evaluating the benefit of using a Procurement Service Provider, see Accenture, 2003). In addition, it would be helpful to analyze the robustness of supply chain decisions to mistaken beliefs. Alternatively, rather than enriching Bayesian models of beliefs, one can adopt an entirely different approach and explore non-Bayesian, belief-free models of information asymmetry as in Sharma et al. (2009). The presence of asymmetric information also can cause moral hazard problems in decentralized supply risk management. For example, when a buyer commits to subsidizing a risky supplier, the buyer might unintentionally be encouraging the supplier to take further risks that are not in the buyer's best interest.

An interesting direction for future research is to analyze cooperative decision-making in the presence of supply risk. For example, suppliers may collude, thus changing the buyer's risk profile. 
Likewise, a group of buyers may cooperate to make group purchases, which would then lead to questions about how they should allocate the supply risk among themselves. Furthermore, suppliers and buyers may cooperate to make the supply chain more resilient to risks as long as both parties benefit from such concerted efforts.

For methodological approaches to supply risk management, an important distinguishing characteristic of the supply risk is whether or not it is priced by financial markets. A related practical question is whether financial instruments can be used to manage supply risks, and how such instruments would interact with traditional operational tools such as backup production and multi-sourcing. If financial replication is not possible, perhaps actuarial risk measurement and management can be used instead. Likewise, the relatively more mature field of quality control may provide inspiration for managing supply risks in decentralized networks (e.g., see Zipkin, 2009).

Much of the extant research literature focuses on supply risk as it applies to quantity, i.e., an order not being filled in full. Identifying and studying other forms of supply risk would be a valuable research direction. For example, one important type of supply risk, delayed delivery of an order, is understudied and worthy of further consideration. Such delays are particularly relevant in decentralized environments, where a buyer's ability to meet its own deadlines may require successful coordination of deliveries from several independent suppliers.

Another connection that is worthy of further research is the one between risk management and product design. A manufacturer's product design is often closely linked to its supply chain configuration, which in turn influences the manufacturer's supply risk. For example, one could investigate the risk implications of using modular products, which require the final assembler to put together a few modules built by subassemblers, versus non-modular products, which require the final assembler to combine a large number of parts and components. The former design type leads to long supply chains with fewer suppliers at each echelon, whereas the latter design type leads to shorter supply chains with many suppliers at each echelon (Bernstein and DeCroix, 2004; Wang et al., 2009). Such different supply chain structures have a significant effect on the final assembler's vulnerability to supply risks.

Finally, as discussed in the Introduction, there are myriad causes of supply disruptions, and future research may move beyond generic models of supply risk to look deeper into specific causes of supply disruptions. For example, a plant fire and an impasse in labor negotiations may be similar as far as their end results are concerned - both will cause a temporary halt in production. However, the preparedness and recovery plans for a disruption caused by a plant fire may be significantly different from the plans that are in place for labor negotiations. High-fidelity models, which capture considerations that are relevant to specific causes of supply risks, may be used for prescriptive purposes in supply risk management. 


\section{References}

Accenture 2003. Executive insights into the growing use of procurement outsourcing. 2003 procurement survey.

Babich, V. 2006. Vulnerable options in supply chains: Effects of supplier competition. Naval Research Logistics 53(7) $656-673$.

Babich, V. 2009. Independence of capacity ordering and financial subsidies to risky suppliers. Working paper, Department of Industrial and Operations Engineering, University of Michigan.

Babich, V., A. N. Burnetas, P. H. Ritchken 2007. Competition and diversification effects in supply chains with supplier default risk. MESOM 9(2) 123 - 146.

Baiman, S., P. E. Fischer, M. V. Rajan 2000. Information, contracting, and quality costs. Man. Sci. 46(6) $776-789$.

Bernstein, F., G. A. DeCroix 2004. Decentralized pricing and capacity decisions in a multi-tier system with modular assembly. Man. Sci. 501293 - 1308.

Bertrand, J. 1883. Theorie mathematique de la richesse sociale. Journal des Savants 67 499-508.

Biddle, F. M. 1997a. Boeing effort to cushion itself from cycles backfires — production overhaul hinders plane maker's ability to handle order boom. Wall Street Journal (Eastern edition) Oct 24, 19971.

Biddle, F. M. 1997b. Boeing to miss 12 deliveries in september. Wall Street Journal (Eastern edition) Sep 16, 1997 A.2.

Casey, N. 2007. Mattel issues third major recall; top toy brands barbie, fisher-price are latest facing lead-paint issues. Wall Street Journal (Eastern edition) Sep 5, 2007 A.3.

Chaturvedi, A., V. Martínez-de-Albéniz 2008. Optimal procurement design in the presence of supply risk. Working paper, IESE Business School, University of Navarra, Spain.

Costello, M. 2008. Shipping insurance cost soars with piracy surge off somalia. The Times.

Cournot, A. 1838. Recherches sur les Principes Mathematiques de la Theorie des Richesses. Paris, France: Hachette.

Deo, S., C. Corbett 2008. Cournot competition under yield uncertainty: The case of the us influenza vaccine market. Working paper, Kellogg School of Management and UCLA Anderson School of Management.

Federgruen, A., N. Yang 2009. Competition under generalized attraction models: Applications to quality competition under yield uncertainty. Working paper, Graduate School of Business, Columbia University.

Froot, K., D. Scharfstein, J. Stein 1993. Risk management: Coordinating corporate investment and financing policies. Journal of Finance pp. 1629-1658.

Gurnani, H., M. Shi 2006. A bargaining model for a first-time interaction under asymmetric beliefs of supply reliability. Man. Sci. 52(6) $865-880$. 
Hendricks, K. B., V. R. Singhal 2003. The effect of supply chain glitches on shareholder wealth. Journal of Management 21501 - 522.

Jennings, D. 2002. The best law X 4 X far?. Supply Management 7(6) $40-41$.

Karnani, A. 1985. Strategic implications of market share attraction models. Management Science pp. 536-547.

Lim, W. S. 1997. Producer-supplier contracts with incomplete information. Man. Sci. 47(5) 709715.

McCracken, J. 2006. Ford gets cut off by top supplier in push against detroit squeezes. Wall Street Journal (Eastern edition) Oct 18, 2006 A.3.

Moorthy, K. 1985. Using game theory to model competition. Journal of Marketing Research pp. 262282.

Morse, A. 2006. Laptop makers may seek redress from sony due to battery recall. Wall Street Journal (Eastern edition) Oct 17, 2006 B.3.

Myers, R. 2007. Food fights. CFO Magazine.

Nishiguchi, T., A. Beaudet 1998. The Toyota group and the Aisin fire. Sloan Management Review 40(1) $49-59$.

Papadakis, I. S. 2003. On the sensitivity of configure-to-order supply chains for personal computers after component market disruptions. International Journal of Physical Distribution $\&$ Logistics Management 33(10) 934-950.

Savage, M. 1999. Component aftershock hits channel. Computer Reseller News Oct 18, $1999(864) 166$.

Schweitzer, M. E., G. P. Cachon 2000. Decision bias in the newsvendor problem with a known demand distribution: Experimental evidence. Man. Sci. $46404-420$.

Sharma, S., V. Babich, D. Teneketzi, M. V. Oyen 2009. A decentralized mechanism implementing in Nash equilibria the optimal centralized solution of a supply-chain problem. Working paper, University of Michigan.

Sheffi, Y. 2005. The Resilient Enterprise: Overcoming Vulnerability for Competitive Advantage. The MIT Press.

Swinney, R., S. Netessine 2009. Long-term contracts under the threat of supplier default. Manufacturing $\&$ Service Operations Management 11(1) 109.

Tang, S. Y., P. Kouvelis 2009. Supplier diversification strategies in the presence of yield uncertainty and buyer competition. Working paper, University of Miami.

Wadecki, A., V. Babich 2009. Subsidizing risky suppliers: A comparison of supply chain structures. Working paper, Department of Industrial and Operations Engineering, University of Michigan.

Wall Street Journal 2007. Spinach recall weakens trust in vegetable safety. Wall Street Journal (Eastern edition) Feb 5, 2007 B.2. 
Wan, Z., D. R. Beil 2008a. Bargaining power and supply base diversification. Working paper, Ross School of Business, University of Michigan.

Wan, Z., D. R. Beil 2008b. RFQ auctions with supplier qualification screening. Forthcoming in Operations Research.

Wang, H., G. Aydin, J. Hu 2009. A complexity model for assmebly supply chains in the presence of product variety and its relationship to cost. Working paper, University of Michigan.

White, G. L. 2000. Unruly element: Russian maneuvers are making palladium ever more precious - they force detroit to pay soaring prices for a metal that's used in most cars - tapping a mine in montana. Wall Street Journal (Eastern edition) Mar 6, 2000 A.1.

White, J. 2005. Ford to pay up to $\$ 1.8 \mathrm{~b}$ on Visteon. Wall Street Journal May 26 A3.

Wu, Z., T. Choi 2005. Supplier-supplier relationships in the buyer-supplier triad: Building theories from eight case studies. Journal of Operations Management 24(1) 27-52.

Yang, Z. B., G. Aydın, V. Babich, D. R. Beil 2009a. Supply disruptions, asymmetric information, and a backup production option. Man. Sci. 55(2) 192-209.

Yang, Z. B., G. Aydın, V. Babich, D. R. Beil 2009b. Supply disruptions, asymmetric information, and a dual-sourcing option. Working Paper, Department of Industrial \& Operations Engineering, University of Michigan.

Zimmer, K. 2002. Supply chain coordination with uncertain just-in-time delivery. International Journal of Production Economics 77(1) 1-15.

Zipkin, P. 2009. Quality snags in the mortgage-finance supply chain. Working paper, Duke University. 


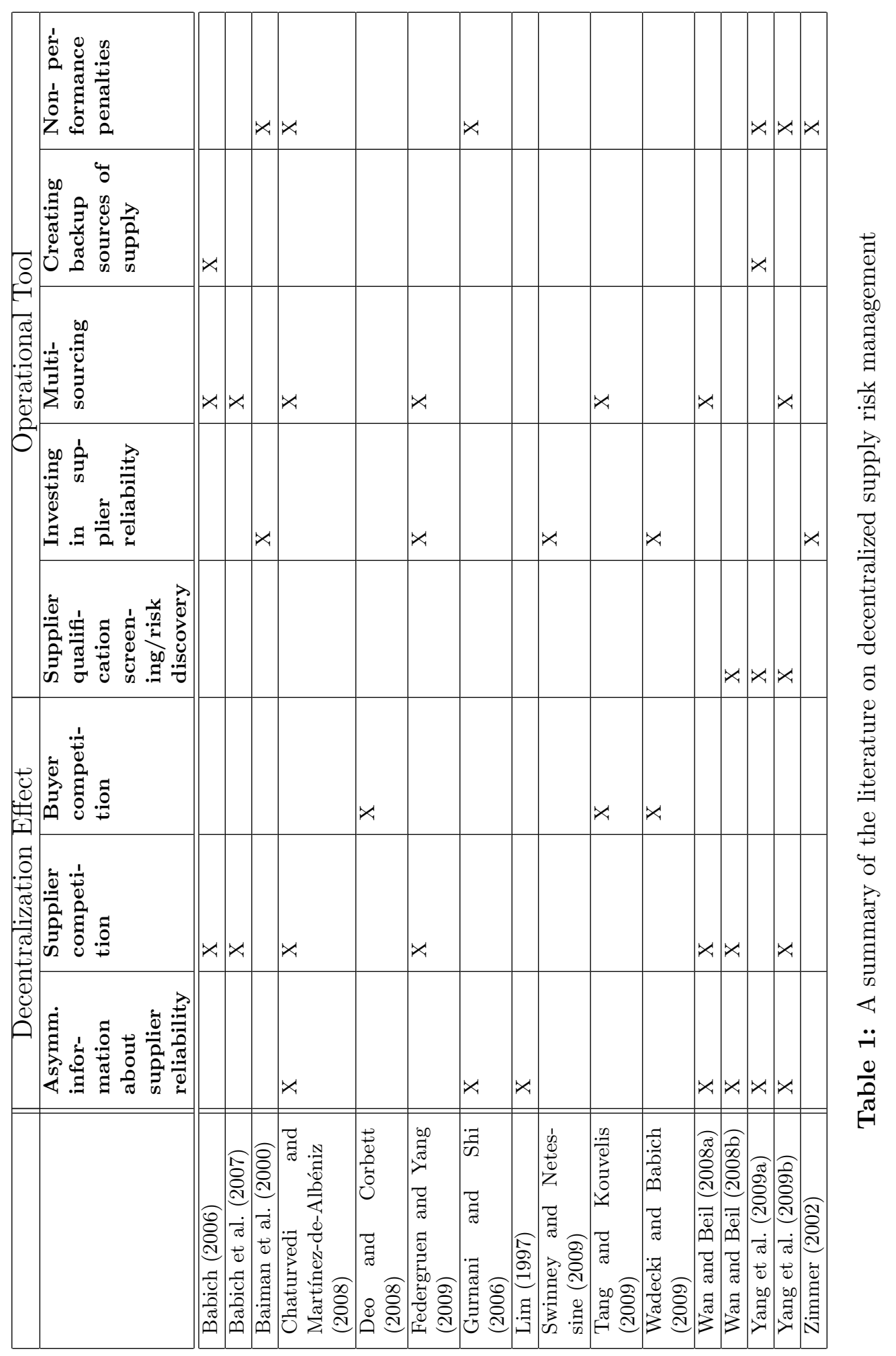

